\title{
Research on Voltage Losses of AT Traction Power Supply System
}

\author{
Yujie Xia, Guosong Lin, Liya Guo, Qiang Li \\ Southwest Jiaotong University, Chengdu, China \\ Email: xiayujie4028@126.com
}

Received April, 2013

\begin{abstract}
Unilateral power supply system has been used because of the management status of the power grid system, while, bilateral power supply system is adopted in the Soviet Union and France. The feasibility that whether bilateral system can be put into applied in China is discussed[1]. Compared with unilateral power supply system, bilateral system has better reliability and better capability of supply power system, which gives bilateral system more advantages over unilateral system on both engineering investment and operating efficiency. In this paper, voltage losses under the two different systems are calculated and also compared, the advantages of bilateral system is explored and then conclusion is drawn by referring to the practical data of passenger transport lines.
\end{abstract}

Keywords: Unilateral AT Power System; Bilateral AT Power Supply System; Voltage Loss; Scheme of Power Supply

\section{Introduction}

With the development of the traction power supply system, there are various power supply modes. In order to meet the requirements of high-speed railway, the auto-passing phase separation system is installed in substation and section post. However, when electric locomotive passes through the device, the over-voltage and over-current frequently occur, as well as the electric railway's reliability and the speed of electric locomotive is affected. If the bilateral power supply is improved, the reliability and power supply capability could be improved, as well as the auto-passing phase separation system can be canceled. In this paper, the bilateral power supply technology for passenger dedicated line is analyzed and researched.

\section{The Models of Unilateral Power Supply and Bilateral Power Supply System}

The theoretical analysis of both unilateral[2] and bilateral AT supply systems is based on the assumptions below: AT transformers are ideal, leakage reactance is ignored, there is no excitation current, steel tracks are insulated to earth, there is no steel track current flowing to line residual current through leakage conductance to earth, and mutual inductance between up and down lines. Derivation can be simplified because of the hypothesis above. Meanwhile, the influences of AT leakage reactance and leakage inductance of tracks to earth on electrical calculation can be counteracted to some degree and the result will be identical to practical model.

\subsection{Unilateral All-parallel AT Power Supply System}

Unilateral power system is shown in Figure 1, and the substations are independent from the others. The electric locomotive obtains power from one conjoint substation.

\subsection{Bilateral All-parallel AT Power Supply System}

Under bilateral power supply system, electric locomotive gets power from two adjacent substations, which is different from the situation under unilateral system. Section posts are built between the substations. Bilateral system is gained through the closure of circuit breakers, which are parallel with neutral section insulators. When one feeding section is faulted, the other feeding section still works. Under bilateral power supply system [5], $2 \times$

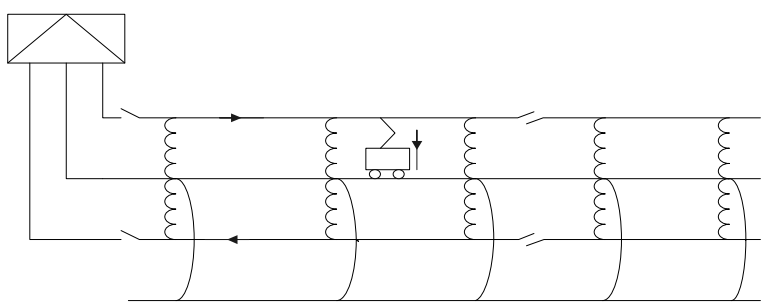

Figure 1. Unilateral all-parallel AT power supply system. $27.5 \mathrm{kV}$ AT supply system is adopted and the bilateral 
system model is shown in Figure 2.

\section{The Theoretical Analysis of Unilateral Power Supply Voltage Loss}

Electric traction network impedance is gained by the equivalent circuit [3], the paper applies original network circuit analysis and calculation of voltage loss needs more complex equations. When many locomotives run on the feeding section, the voltage drop of transmission line is difficult to calculate. Using the conclusion of impedance of traction network, primary circuit can be simplified as shown in Figure 3. With the circuit and the original network reaching the same conclusion, the analysis is more intuitive, convenient and simple to operate [4].

When the feeding arm only has one locomotive $\mathrm{k}$ [4], the train causes the voltage drop by itself:

$$
\Delta \dot{U}=A Z_{A A} \dot{I}_{k}+X Z_{B B} \dot{I}_{k}\left(1-\frac{X}{D}\right)
$$

Below the research of feeding arm within two locomotives for voltage drop interaction, it is assumed that the AT section only has one locomotive, the voltage drop of locomotive $\mathrm{k}$ caused by locomotive $\mathrm{i}$ is:

$$
\Delta \dot{U}_{i k}=Z_{A A} A_{i} \dot{I}_{i}\left(A_{i}<A_{k}\right)
$$

Assume that the AT section only has one locomotive, the voltage drop of locomotive $k$ caused by locomotive $j$ is:

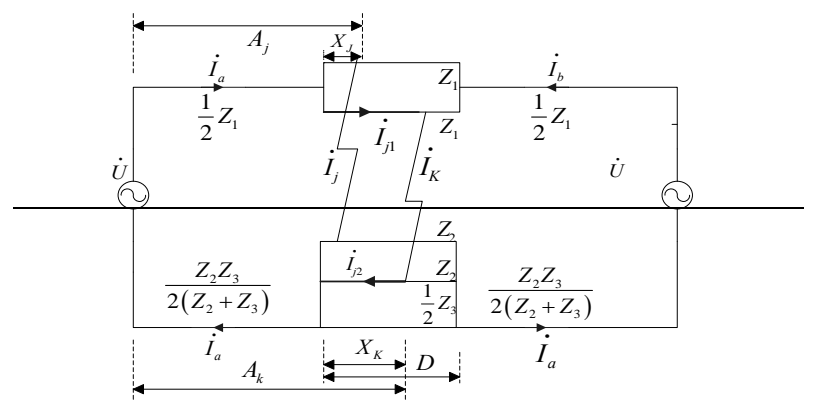

Figure 2. Bilateral all-parallel AT power supply system.

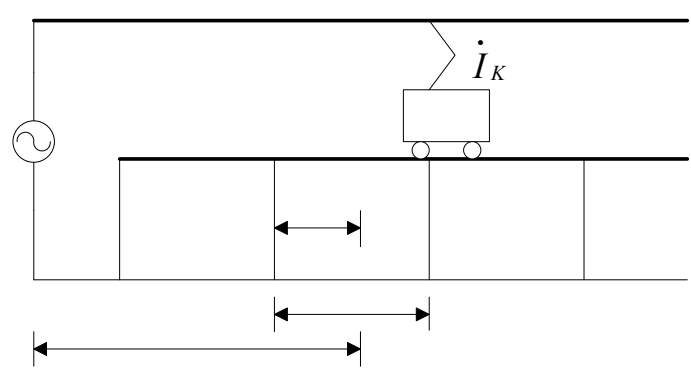

Figure 3. The equivalent circuit diagram of the unilateral all-parallel AT traction system.

$$
\Delta \dot{U}_{j k}=Z_{A A} A_{k} \dot{I}_{j}\left(A_{j}>A_{k}\right)
$$

When the AT sections have many locomotives, considering the mutual influence of the voltage drop between locomotives, the results of an equivalent circuit and all-parallel AT equivalent circuit are similar. When the AT section have two locomotives, the voltage drop of locomotive $\mathrm{k}$ caused by locomotive $\mathrm{j}$ is:

$$
\Delta \dot{U}_{i k}=Z_{A A} A_{i} \dot{I}_{i}+Z_{B B} X_{i} \dot{I}_{i}\left(1-\frac{X_{k}}{D}\right)\left(A_{i}<A_{k}\right)
$$

When the AT section have two locomotives, the voltage drop of locomotive $\mathrm{k}$ caused by locomotive $\mathrm{j}$ is:

$$
\Delta \dot{U}_{j k}=Z_{A A} A_{k} \dot{I}_{j}+Z_{B B} X_{k} \dot{I}\left(1-\frac{X_{j}}{D}\right)\left(A_{\mathrm{j}}>A_{k}\right)
$$

\section{The Theoretical Analysis of Bilateral Power Supply Voltage Loss}

Electric traction network impedance is gained by the equivalent circuit. The paper applies original network circuit analysis and calculation of voltage loss needs more complex equations. When many locomotives are running, the voltage drop of transmission line is difficult to calculate. By using the conclusion of impedance of traction network, primary circuit can be simplified as shown in Figure 4. With the circuit and the original network reaching the same conclusion, the analysis is more intuitive, convenient and simple to operate [4].

When the feeding arm between traction substation A and $\mathrm{B}$ only has one locomotive $\mathrm{k}$, the impedance of power traction system is [4]:

$$
Z=A_{k}\left(1-\frac{A_{k}}{L}\right) Z_{A A}+X_{k}\left(1-\frac{X_{k}}{D}\right) Z_{B B}
$$

So the voltage drop is caused by the locomotive itself:

$$
\Delta \dot{U}=\frac{Z_{A A} \dot{I}_{k} A_{k}\left(L-A_{k}\right)}{L}+\frac{Z_{B B} \dot{I}_{k} X_{k}\left(D-X_{k}\right)}{D}
$$

Assume that the AT section only has one locomotive, the voltage drop of locomotive $\mathrm{k}$ caused by locomotive $\mathrm{i}$ is:

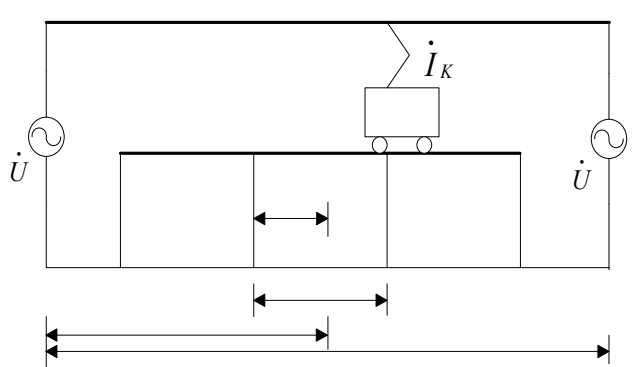

Figure 4. The equivalent circuit diagram of bilateral allparallel AT traction system. 


$$
\Delta \dot{U}_{i k}=\frac{Z_{A A} \dot{I}_{i}\left(L-A_{k}\right)}{L}\left(A_{i}<A_{k}\right)
$$

Assume that the AT section only has one locomotive, the voltage drop of locomotive $k$ caused by locomotive $j$ is:

$$
\Delta \dot{U}_{j k}=\frac{Z_{A A} \dot{I}_{j} A_{k}\left(L-A_{j}\right)}{L}\left(A_{j}>A_{\mathrm{k}}\right)
$$

When the AT section has two locomotives, the voltage drop of locomotive $k$ caused by locomotive $i$ is:

$$
\Delta \dot{U}_{i k}=\frac{Z_{A A} A_{i} \dot{I}_{i}\left(L-A_{k}\right)}{L}+\frac{Z_{B B} X_{i} \dot{I}_{i}\left(D-X_{k}\right)}{D}\left(A_{i}<A_{k}\right)
$$

When the AT section have two locomotives, the voltage drop of locomotive $\mathrm{k}$ caused by locomotive $\mathrm{j}$ is:

$$
\Delta \dot{U}_{j k}=\frac{A_{k} Z_{\mathrm{A} \mathrm{A}} \dot{I}_{j}\left(L-A_{j}\right)}{L}+\frac{Z_{B B} X_{k} \dot{I}_{j}\left(D-X_{j}\right)}{D}\left(A_{j}>A_{k}\right)
$$

When the up and down locomotives are in the same AT section, the equivalent circuit diagram is needed, as shown in Figure 5[4].

When studying locomotive j's influence on the voltage drop of locomotive k. $\dot{\mathrm{I}}_{\mathrm{j} 1}, \dot{\mathrm{I}}_{\mathrm{j} 2}, \dot{\mathrm{I}}_{\mathrm{a}}$ and $\dot{\mathrm{I}}_{\mathrm{b}}$ are obtained as follows: [4]

$$
\left\{\begin{array} { c } 
{ \dot { \mathrm { I } } _ { \mathrm { j } 1 } = \frac { \dot { \mathrm { I } } _ { \mathrm { j } } ( \mathrm { LX } \mathrm { j } _ { \mathrm { j } } - D A _ { j } ) } { 2 \mathrm { L } D } } \\
{ \dot { I } _ { j 2 } = \frac { \dot { I } _ { j } Z _ { 3 } ( L X _ { j } - D A _ { j } ) } { 2 L D ( Z _ { 2 } + Z _ { 3 } ) } }
\end{array} \quad \left\{\begin{array}{c}
\dot{\mathrm{I}}_{\mathrm{a}}=\frac{\dot{\mathrm{I}}_{\mathrm{j}}\left(L-A_{j}\right)}{L} \\
\dot{I}_{b}=\frac{\dot{I} A_{j}}{L}
\end{array}\right.\right.
$$

The voltage drop of locomotive $\mathrm{k}$ caused by locomotive $\mathrm{j}$ is:

$$
\begin{aligned}
\Delta \dot{U}_{j k}= & \frac{Z_{1} \dot{I}_{a}\left(A_{j}-X_{j}\right)}{2}+\frac{Z_{2} Z_{3} \dot{I}_{a}\left(A_{j}-X_{j}\right)}{2\left(Z_{2}+Z_{3}\right)} \\
& +Z_{1} X_{k} \dot{I}_{j 1}+Z_{2} X_{k} \dot{I}_{j 2}
\end{aligned}
$$

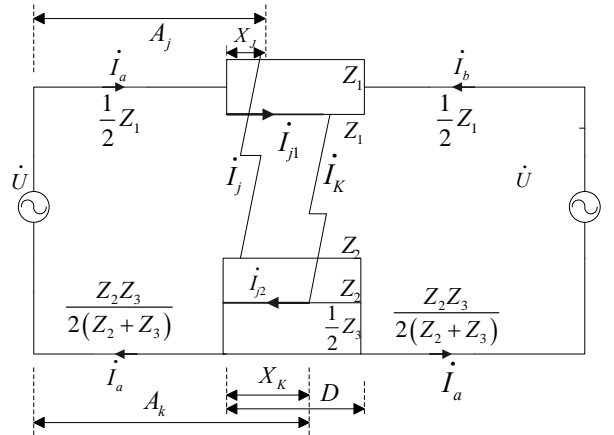

Figure 5. The equivalent circuit diagram of voltage loss.

$$
\Delta \dot{U}_{j k}=\dot{I}_{j} Z_{A A}\left[\frac{\left(L-A_{j}\right)\left(A_{j}-X_{j}\right)}{L}+\frac{X_{k}\left(L X_{j}-D A_{j}\right)}{D L}\right]
$$

Likewise, in the same AT section, the voltage drop of locomotive $\mathrm{j}$ caused by locomotive $\mathrm{k}$ is:

$$
\Delta \dot{U}_{k j}=\dot{I}_{k} Z_{A A}\left[\frac{\left(L-A_{k}\right)\left(A_{k}-X_{k}\right)}{L}+\frac{X_{j}\left(L X_{k}-D A_{k}\right)}{D L}\right]
$$

When calculating the traction network voltage loss, $Z_{A A}$ and $Z_{\mathrm{BB}}$ should be replaced by $Z_{A A}^{\prime}$ and $Z_{B B}^{\prime}$, that is:

$$
\left\{\begin{array}{l}
Z_{A A}^{\prime}=r_{A A} \cos \varphi+x_{A A} \sin \varphi \\
Z_{B B}^{\prime}=r_{B B} \cos \varphi+x_{B B} \sin \varphi
\end{array}\right.
$$

where $\mathrm{r}_{\mathrm{AA}}, \mathrm{x}_{\mathrm{AA}}$ are the real part and imaginary component of the long loop of impedance; $r_{B B}, x_{B B}$ are the real part and imaginary component of the short loop of impedance; $\varphi$ is load power factor angle.

\section{The Comparison between Voltage Loss in Unilateral AT Traction System and in Bilateral System}

The impedance characteristics of unilateral and bilateral all-parallel AT traction system are discussed in reference [4], and their characteristic curves are saddle-shaped. The peak voltage loss is not in the end of AT power supply system, so we should calculate the voltage loss of locomotives according to the change of tracking interval, and then, maximum voltage loss is gained by comparing and analyzing the data.

\subsection{The Voltage Loss Calculation of Unilateral Power Supply System}

The peak of voltage loss will occur in the last locomotive when there are many locomotives on the feeding section. So in this paper, we only calculate the last locomotive's voltage loss. Table 1 shows the position and peak voltage loss of the locomotive less than 3 minutes tracking interval condition, and the position and peak voltage loss of the locomotive under 4 minutes interval condition is shown in Table 2.

From the data above, it can be deduced that the peak voltage loss occurs in the end of the last locomotive.

When tracking and observing the locomotive in every 3 minutes; while, under 4-minute interval condition, the peak voltage loss occurs at the last locomotive which is 1 $\mathrm{km}$ away from the end of the feeding section. So the peak voltage mostly occurs at the section where there are the most locomotives running under feeding section. 
In the case of 3 minutes interval, there are 5 locomotives at most and 4 at least in $60 \mathrm{~km}$ feeding arm. In the case of 4 minutes interval, there are 4 locomotives at most and 3 at least, and the location will change $1 \mathrm{~km}$ every time from the left substation A, which is considered as the initial position. In Tables 3 and 4, voltage loss of the locomotives (those locomotives' maximum voltage loss may occur) at corresponding position is calculated.

From the Table above, it can be seen that the peak voltage loss will occur in the end of the last locomotive when the interval is 3 minutes, while, the peak loss will occur 1 kilometer apart from the end of the last locomotive when the interval is 4 minutes. Therefore, the location where peak loss occurs is not fixed.

\subsection{Comparison between Unilateral and Bilateral Peak Voltage Loss}

The comparison between unilateral and bilateral all-parallel AT power supply systems under 3 and 4 minutes interval are shown in Table 5. As is seen in Table 5, the bilateral traction power supply network can save over $15 \%$ of the voltage loss of unilateral traction network. Therefore, the length of feeding arms can be increased when the voltage loss is the same under these two different systems.

Table 1. The locomotive position and voltage in the case of 3 minutes.

\begin{tabular}{ccccc}
\hline The locomotive $1 / \mathrm{km}$ & 0 & 1 & 2 & 4 \\
\hline The locomotive $2 / \mathrm{km}$ & 13.5 & 14.5 & 15.5 & 16.5 \\
The locomotive $3 / \mathrm{km}$ & 27 & 29 & 29 & 30 \\
The locomotive $4 / \mathrm{km}$ & 3.96 & 4.0944 & 4.2066 & 4.283 \\
\hline
\end{tabular}

Table 2. The locomotive position and voltage loss in the case of 4 minutes.

\begin{tabular}{ccccc}
\hline The locomotive $1 / \mathrm{km}$ & 0 & 1 & 2 & 3 \\
\hline The locomotive $2 / \mathrm{km}$ & 22.5 & 23.5 & 24.5 & 25.5 \\
Peak voltage loss $/ \mathrm{kV}$ & 2.666 & 2.8261 & 2.9606 & 3.0695 \\
The locomotive $1 / \mathrm{km}$ & 4 & 5 & 6 & 7 \\
The locomotive $2 / \mathrm{km}$ & 26.5 & 27.5 & 28.5 & 29.5 \\
Peak voltage loss $/ \mathrm{kV}$ & 3.152 & 3.2105 & 3.2426 & 3.249 \\
\hline
\end{tabular}

Table 3. The locomotive position and voltage loss in the case of 3 minutes.

\begin{tabular}{cccccccc}
\hline The distance from the initial position $/ \mathrm{km}$ & 0 & 1 & 2 & 3 & 4 & 5 & 6 \\
\hline The locomotive 2 voltage loss $/ \mathrm{kV}$ & 2.3022 & 2.2754 & 2.3943 & 2.6589 & 2.8898 & 3.0808 & 3.2317 \\
The locomotive 3 voltage loss $/ \mathrm{kV}$ & 3.3794 & 3.2874 & 3.1617 & 2.9832 & 3.1617 & 3.2874 & 3.3794 \\
The locomotive 4 voltage loss $/ \mathrm{kV}$ & 3.2317 & 3.0808 & 2.8898 & 2.6589 & 2.3943 & 2.2754 & 2.3022 \\
\hline
\end{tabular}

Table 4. The locomitive position and voltage loss in the case of 4 minutes.

\begin{tabular}{lccccccc}
\hline The distance from the initial position $/ \mathrm{km}$ & 0 & 1 & 2 & 3 & 4 & 5 \\
\hline The locomotive 2 voltage loss $/ \mathrm{kV}$ & 2.3288 & 2.512 & 2.658 & 2.7669 & 2.8386 & 2.8732 \\
The locomotive 3 voltage loss $/ \mathrm{kV}$ & 2.8706 & 2.8732 & 2.8386 & 2.7669 & 2.658 & 2.512 & 2.8706 \\
\hline
\end{tabular}

Table 5. Traction network peak voltage loss of unilateral and bilateral power supply.

\begin{tabular}{lcc}
\hline \multicolumn{1}{c}{ The time interval } & 3min & $4 \mathrm{~min}$ \\
\hline $\begin{array}{l}\text { The peak voltage loss of unilateral } \\
\text { power supply / } \mathrm{kV}\end{array}$ & 4.2803 & 3.6381 \\
$\begin{array}{l}\text { The peak voltage loss of bilateral } \\
\text { power supply / } \mathrm{kV}\end{array}$ & 3.571 & 2.8732 \\
$\begin{array}{l}\text { The voltage loss reduced/The voltage } \\
\text { loss of unilateral power supply /\% }\end{array}$ & 16.57 & 21.02 \\
$\begin{array}{l}\text { The minimum voltage of unilateral } \\
\text { power supply / } \mathrm{kV} \\
\begin{array}{l}\text { The minimum voltage of bilateral } \\
\text { power supply } / \mathrm{kV}\end{array}\end{array}$ & 21.5082 & 23.2209 \\
\hline
\end{tabular}

\section{Conclusions}

After the models of unilateral and bilateral power supply systems are analyzed and calculated, it can be concluded that the voltage loss of bilateral power supply system can be decreased by $10 \%$ or more compared with that of unilateral system. Besides, the lowest voltage of bilateral system is higher than that of unilateral system, which guarantees both the reliability and better capability of power supply. Therefore, the application of bilateral power supply system will be well worth exploring.

\section{Acknowledgements}

The authors acknowledge the supports of the Ministry of 
Railways Technology Research and Development Plan of China (Grant No. 2011J017-B) and the Fundamental Research Funds for the Central Universities (Grant No. SWJTU12CX034).

\section{REFERENCES}

[1] Z. L. Li, W. Chen and P. Dang, "The Principle Analysis of Auto-transformer in Electrified Railway," Journal of East China Jiaotong University, 1993, pp. 48-53.

[2] X. F. Zhang, "The Research on Co-phase at Traction
Power Supply in the Rapid Transit Railway,"Southwest jiaotong university dissertation, 2006.

[3] C. S. Xin, "Equivalent Circuit Method of the AT Power Supply System,” Electrified railway, 1995.

[4] Q. Li, "Study on Protective Schemes of Bilateral Traction Power Supply Systems for High Speed Railways,” 2011, pp. 21-24.

[5] Q. Z. Li and J. M. He, "The Analysis of Power Traction System,” Southwest Jiaotong university press, 2007, pp.10-13. 